\title{
Reflections on Choice and Agency in Context: a Reply
}

\author{
Alex R. Piquero ${ }^{1,2}$
}

Received: 11 July 2021 / Revised: 11 July 2021 / Accepted: 2 August 2021 /

Published online: 26 August 2021

(c) The Author(s), under exclusive licence to Springer Nature Switzerland AG 2021

"Free will and determinism are like a game of cards. The hand that is dealt you is determinism. The way you play your hand is free will." - Jawaharlal Nehru

I have been asked by the editors to respond to Thomas et al.'s rejoinder to commentaries on Paternoster's (2017) paper on human agency by Cullen, Brezina, and myself (though to be clear, I was asked to comment on the Paternoster, Cullen, and Brezina exchanges). I am not necessarily of the mind that Thomas et al. have contributed anything new here, other than to simply restate much of Paternoster's arguments and where they believe Cullen, Brezina, and I are "confused" or have "misunderstood" things. To play off one popular Genesis song, I can say here that there was no misunderstanding on my part on what Paternoster's view of agency was, nor do I and I believe both Cullen and Brezina, in the lyrics of another Genesis song, live in a land of confusion. Thomas et al. simply disagree with my and/or others' views. Yet, disagreement does not equate with misunderstanding.

Let me be very clear. I never stated that unless agency can be measured it is not a relevant theoretical construct. And while it may not be entirely nor always necessary to measure agency, observing its systematic consequences is sufficient and directly measuring it is even more desirable. This, after all, permits us to assess whether a theory's key predictions are upheld. In short, Thomas et al. simply misconstrue, misunderstand, and misspeak on behalf of Paternoster. In the remainder of this response, I highlight the key points.

First off, I accept the position that the defining characteristic of humans is intentionality, the capacity for reason, etc. I have no problem with Thomas et al. noting that "All humans have the capacity for reflection, intentionality, and evaluation, even criminologists!" This is their background assumption. And of course, it is the assumption underlying the work of Laub and Sampson. But if that is true and all have it, then why does behavior vary? Thomas et al. provide an answer in one of their critiques of my work on intermittency, where I indicate, they claim incorrectly,

Alex R. Piquero

axp1954@miami.edu

1 Department of Sociology \& Criminology, University of Miami, 5202 University Avenue, Merrick Building, Coral Gables, FL 33124, USA

2 Monash University, Criminology, Melbourne, Australia 
that intermittent or zig-zag patterns of offending over time show that agency is variable. Thomas et al. retort (emphasis added): "They do not. It may just as well be that all people possess human agency, entirely consistent with Paternoster, and that intermittent offending results from structural perturbations in legal and illegal opportunities that arise intermittently..." that would be exogenous factors, or causation, in typical terms. A constant like agency, as Thomas et al. define it, cannot explain differences. Thomas et al. continue: "Further, some individuals (like Paul) may get married but still offend, and others (most) may choose to desist from crime without ever getting married. Such individuals are difficult to explain from typical positivist theories (e.g., Laub \& Sampson, 2003), but are easily accounted for in theories embracing human agency (Paternoster \& Bushway, 2009)." How so? If all humans possess agency, then it does not explain Paul vs. Peter. And unless one assumes perfect determinism, Paul's offending while married is not a problem. Besides, Laub and Sampson's counterfactual comparison, at least in theory, was Paul's rate of offending before and after marriage. If it declined, that is evidence of an effect, even if he still offends. Drinking two Manhattan's a night instead of four every night could be progress, at least as measured by some advocating reduced alcohol consumption! In short, for the concept of agency to have meaning and utility, we must go beyond background assumption. Why behavior varies cannot be explained by a background assumption. We need to press ahead and look at manifestations, in choices and settings. I am not alone.

One of Paternoster's long-time co-authors, who I have also written with, Daniel Nagin (2007) in his Sutherland Address to the American Society of Criminology, sought to move choice to the center stage of criminology (see also Gottfredson \& Hirschi, 2020, p. 118). Although there is an abundance of important material in Nagin's essay, the most relevant for present purposes is his critique that theories of crime lacked "any sense of people making choices, what is sometimes called human agency" (p. 261). He further cites an important statement by Lilly et al., (2006, p. 261): "unless human agency can be operationalized, scholars cannot test empirically whether this is an important causal factor that explains variation in offending or merely reflects self-serving or distorted memories related by old criminals about their past lives in crime."

I continue to believe that human agency is more than a background assumption. Human agency does not operate the same way throughout the life course, nor the same under hot/cold conditions, and so forth. It is variable, between persons, within persons, across situations, and over time. As such, I believed then and continue to believe today that the greatest use for human agency lies in the extent to which it can be conceptualized, operationalized, and then empirically tested. By doing so, it opens up many research opportunities in developmental and life course criminology. Just because Paternoster warned against measuring the concept does not mean that it should not be. On this score, Nagin himself agrees.

After highlighting Lilly et al.'s point about the operationalization of human agency, Nagin doubles down: "I want to take up their challenge because they are right: Unless agency can be used as an organizing structure for testing important propositions, it is no more than a slogan. By agency I mean a decision-making process, however crude or faulty, that reflects the benefits, costs, and risk of alternative 
courses of action...I will argue that it is a conception of agency that can be made operational to address issues that are central to criminology and that research on these issues does not have to wait for advances in theory, measurement, or methodology" (p. 262, emphasis added). ${ }^{1}$ Moreover, economists, and indeed the entire discipline of economics, rely on the concept of choice. It is formalized in mathematical models and studied empirically in discrete choice models (among other methods), and structures of opportunity have causal importance. The whole point of discrete choice models is that you make decisions within available structures. Exogenous events can change those structures, modifying your choice set and thus choices (see, e.g., Laub \& Sampson, 2003). The idea that social causation (e.g., labor market changes) is incompatible with choice or agency would be unfathomable to an economist.

Just a few years after Nagin's paper, Paternoster collaborated with Greg Pogarsky, whom I have also written with on decision-making, in what I think to be a very important contribution to agency and decision-making, and specifically on how it is to be operationalized. Leaving aside the fact that, surprisingly, Thomas et al. failed to draw attention to this important work, Paternoster and Pogarsky undertook "an important project for criminologists-specifying what we take to be a critical element of human agency, TRDM [thoughtfully reflective decision making], linking it within a broad theoretical position, rational choice theory, and operationalizing it in a manner that allows us to investigate its empirical implications. [Their] claim [was] that an important part of what it means to act rationally and with agency is the process of thoughtfully reflective decision making" (2009, pp. 120-121). These authors linked both rational choice and human agency to TRDM, which has four key components: (1) collecting information pertaining to a problem that requires a decision; (2) thinking of alternative solutions to the problem; (3) systematically deliberating over how to determine which alternative might be best; and (4) retrospectively analyzing how good a problem solver one was in the situation (p. 121). According to these authors, TRDM is a characteristic of individuals that varies both across and within persons over time as well as across different contexts and situations where decisions are made. Paternoster and Pogarsky (2009, p.106) further contend that TRDM can offer criminologists (and decision-making scholars more generally) with an important tool in their toolbox in large part because "discussions of human agency have been too long divorced from the empirical world." Thus, "human agency is revealed at least in part through thoughtful reflection and deliberative action" (p. 111).

Using data from the Add Health, Paternoster and Pogarsky developed an initial measure of TRDM that captured the themes outlined above and found that respondents who scored higher on TRDM had more favorable outcomes in the short and long term. As well, those reporting greater TRDM were less likely to be involved in delinquency, heavy drinking, and drug use, and were more likely to expect to graduate from college. Paternoster and Pogarsky summarized their investigation in the following manner: "In this paper we have taken the first steps in what we think is an

\footnotetext{
1 I think it is fair to assume that Nagin's "organizing structure for testing important propositions" is the equivalent to a variable that can be measured and about which predictions can be made.
} 
important project for criminologists - clearly specifying what we take to be a critical element of human agency, TRDM, linking it within a broad theoretical position, rational choice theory, and operationalizing it in a manner that allows us to investigate its empirical implications" (pp. 120-121). And they concluded by acknowledging that "our operationalization is only one possibility and we welcome other efforts to provide empirical referents to notions of human agency. Additional conceptual work is also clearly in order. There are likely other components to human agency than simply TRDM, although we here argue it is an important dimension. Further empirical work is in order as well. We have suggested that TRDM improves over the life course, which if true it would naturally be implicated in the process of desisting from crime" (p. 121).

In short, I believe that neither Brezina nor I misunderstood or misapplied Paternoster's notion of human agency. Our understanding of it is more than reasonable. But, we simply do not exclusively view agency as some unmeasurable "background" assumption but a concept whose real-world manifestations can and should be examined. Thomas et al. seem to be confusing our different perspectives as evidence that we do not understand Paternoster's argument. Let me restate again: disagreement does not imply misinterpretation.

In fact, Paternoster himself expressly called for "rescuing human agency from the "subjective ghetto" (Emirbayer \& Mische, 1998: 991) in that it has an empirical referent" (Paternoster \& Pogarsky, 2009, p. 113, emphasis added). Paternoster and Pogarsky go on to cite the same Lilly et al. passage that Nagin did, where they describe the importance of operationalizing human agency and conclude by noting that their "position is what we call TRDM consists of making good choices, that it is the most effective way to make choices consistent with preferences, and that it reflects what it means to act with agency" (p. 113, emphasis added). Therefore, TRDM is "one element of human agency" (Paternoster \& Pogarsky, 2009, p. 106). The bottom line: human agency, or its manifestations, can, should, and must be operationalized in order to examine its viability for understanding decisions and outcomes.

To be sure, Paternoster and Pogarsky were not the first to call attention to the issue of human agency, to include any potential empirical referents. For example, Laub and Sampson (2003, p. 281), whom seem to have been the impetus for Paternoster's work on human agency, advance both human agency, or "the purposeful execution of choice and individual will (Matza, 1964)" (Laub, 2006, p. 244), and other causal factors into their analysis, such that "the interaction between life course transitions, situational context, and individual will" is needed when considering desistance. Thus, when thinking about situated choice, i.e., how the choice dimension of agency is very intimately connected to the social bonds dimension, "there is no hypothetical moment at which agency actually gets 'free' of structure...[in] some pure Kantian transcendental will" (Emirbayer \& Mische, 1998, 1004). There is no such thing as "unsituated choice," that was the precise (and I believe correct) point that Laub and Sampson were making. ${ }^{2}$

\footnotetext{
${ }^{2}$ It is worth noting that Thomas et al.'s attack on Laub and Sampson borders on the absurd. To say that marriage or employment or any other cause denies that people have any agency is frivolous, especially because Laub and Sampson never said as such. On this point, Thomas et al. state: "One cannot say that
} 
Intriguingly, Thomas et al.'s framework makes some distinction(s) between the caused and the chosen, which of course raises the question "how do we know the difference between the caused and the chosen?" (Bottoms, 2006, p. 260). If we were to adopt such a distinction, how-in a social scientific analysis-would we know what is "caused" and what is "uncaused"? (Bottoms, 2006, p. 281). People have potentially genuine reasons for the choices they make and some social pressures backing up the various options (Bottoms, 2006, p.282, emphasis in original): "While these are reasons rather than causes, the explanatory analysis is fundamentally similar; we can explain either decision. Thus, for the purposes of explanation, in ordinary science there is little purpose in troubling ourselves with the philosophical distinction between the "reasons" and "causes", the "uncaused" and the "caused"." Yet, as Bottoms (2006, p.282) observes, what may prove more difficult for the social scientist is in fact not explanation but the prediction of which choice an individual would make. ${ }^{3}$ More to the point: if my "reasons" are why I do something, then in a counterfactual logic, without my reasons I would not have done something!

Aside from Laub and Sampson, who I believe are correct in noting that you cannot understand choices absent in the environment within which they are made, I find Wikström's $(2006,2017,2018)$ view of human agency within his situation action theory (SAT) to be theoretically and empirically useful. In SAT, agency is defined as "powers to make things happen intentionally," and people are assumed to have different strengths of agency depending on their human, financial, and social capital (i.e., action-relevant personal resources) and their thereupon-based belief in their capacity to make certain things to happen. In SAT, agency is not only seen to vary between people but also by age (for example, toddlers have very little agency). ${ }^{4}$ In contrast to other perspectives, agency within SAT is not the same as choice but something that effects the efficacy of one's choices. In SAT, agency is context-dependent, people have more agency in some circumstances than others (e.g., Wikström, 2006, pp. 79,

\section{Footnote 2 (continued)}

individuals act with purpose, reflection and intentionality, and then suggest that major events like marriage are fortuitous." Of course you can. Thomas et al. are incorrect to imply that this is some sort of 15-min "event" at the altar. The processes leading to marriage, such as meeting a future partner, are governed by all sorts of things we do not necessarily control. Matchmaking, sex ratios, societal norms about marriage, arranged marriages, random encounters, etc. Of course, we do not also choose and/or control the actions of others, directly implied by Thomas et al.'s argument. So, if exogenous labor market changes lead women to work more and decide to marry less, men's choices are affected-causally! Or when the Glueck man's wife supervised and controlled her man's drinking habits, by definition in Thomas et al.'s perspective, she had agency, which created a situation which can have causal effects.

3 I suspect that many will find Thomas et al.'s distinction between "reasons" and "causes" less than convincing. What is the substantive difference between saying " $X$ caused $Y$ " and saying "the reason $Y$ looks the way it does is because of $X$ "? Whatever difference that exists between those two is a social construction because the bottom line is they are still using causal language. That is, is there really no causality involved when one says "agency is the reason we do something"? Of course there is causality inferred there.

4 Wikström (2005, p.224) argues that, at the start of their lives, individuals have "practically no agency," but as they age and develop they acquire "a greater potential to influence their activity field (a stronger agency)...This is partly a consequence of organismic change (e.g., biological maturation) and partly a consequence of increased experiences and (culturally age-defined) increases in social independence" (Bottoms, 2006, p.273). 
83-84). Thus, there is undoubtedly likely to be wide variation in people's ability to exercise their agency due to some individual, contextual, or structural characteristic and different facets of human agency can help us understand why one person may be more or less likely to engage in agentic actions and why someone else does not across situations, contexts, and periods of the life course. ${ }^{5}$ In fact, the United States Supreme Court recognized the variation in culpability among juvenile offenders who have committed homicide at certain ages: Roper considered juveniles' lack of maturity and responsibility, their vulnerability to negative influences, and their transitory and developing character when it increased the minimum age for death eligibility from 16 to 18 (543 US at 569-570) (see Monahan et al., 2015). In sum, it is not hard to envision the possibility of constructing acceptable measures for aspects of human agency and in fact, it could also be possible to construct measures targeting how successful people actually are to accomplish their desires (as a measure of their actual agency).

Finally, in their most recent writings on control theory, Gottfredson and Hirschi (2020, p. 120) remind readers that "the theory of choice does not require or imply active or conscious decision-making in every context." Plenty of actions operate, as they say, "outside conscious awareness and intention" (p. 120). ${ }^{6}$ For these theorists, "Self-control is agency. It is the tendency to consider-however wittingly or unwittingly, well or erroneously perceived-the consequences of one's acts and to behave accordingly" (p.125). And of course, there are many different ways of conceptualizing (Hirschi, 2004; Marcus, 2003; Piquero \& Bouffard, 2007; Vohs \& Piquero, 2021) and measuring self-control (Piquero et al., 2000), but nevertheless we know that it is variable and can be measured and it has proven to be an important contribution to the field.

Aside from the important work in criminology, other disciplines have provided definitions and conceptualizations of human agency, because after all, as is the case with theories (Tittle, 1995, p.89), no single person has sole copyright on human agency. Here, I provide some useful examples, but quite a few others, including recommendations for measuring human agency existing elsewhere (see, e.g., Moore, 2016; Tapal et al., 2017).

Goller and Harteis (2017) provided researchers, primarily in the field of workplace relations and workplace learning, with a clarification on what human agency is and an operationalization of the concept. Defining human agency as "how human beings are agents of influence who are able to cause things and bring about change" (p.85), these authors discuss human agency from two different perspectives, agency as something individuals do and agency as a personal feature of individuals. The

\footnotetext{
5 The same is true, of course, with respect to individual variation in deterrence across persons and situations (see Piquero, Paternoster, Pogarsky, \& Loughran, 2011). In fact, two of the authors themselves, in a paper co-authored with me, found that individual characteristics help to explain variation in sanction risk updating (Thomas, Loughran, \& Piquero, 2013).

${ }^{6}$ Hirschi (1986, p. 115) makes a key observation about the level of planning and foresight in choicerelated theories: "Accepting a choice model does not require that we assume planning or foresight beyond the bare minimum necessary for the act to occur. If greater levels of planning and foresight were required by a choice model, I believe the model would be in trouble."
} 
former considers human agency as being manifested when people make choices and then act based on those choices, while the latter views individuals as agentic, frequently exercising agency and actively taking control over their lives and environments (p. 87).

After combining both perspectives into a single theoretical framework, Goller and Harteis then derive three distinct components of human agency: (1) agency competence, (2) agency beliefs, and (3) agency personality. Agency competence involves the "competence to initiate and engage in agentic actions" (p. 91). Agency beliefs center around an individual's perception "of whether or not they have the abilities to engage in agentic actions" (p. 93) As Bandura has argued and shown, individuals must believe in themselves in the first place if they are able to see that they can do something. This notion of self-efficacy has a long-standing claim of empirical support. Lastly, agency personality can be "defined as the stable and comparably situation-unspecific inclination to make choices and to engage in actions based on these choices with the aim of taking control over one's life or environment" (p. 94).

Toward that end, Goller (2017) used these three facets to operationalize human agency. Specifically, the employed measures (agency competence, self-developed scale; agency beliefs, work-specific self-efficacy beliefs...; agency personality, need for control in work settings) were then latently measured as a combination of the three facets and were found to predict "geriatric care nurses' engagement in different agentic actions: deliberate participation in institutionalized learning activities like training; deliberate crafting of new experiences at work, deliberate inquiry of codified information through readings journals, books, or web resources; and deliberate efforts to initiate constructive change at work" (Goller \& Harteis, 2017, p.96).

\section{Conclusion}

Several scholars have lamented about the lack of consensus regarding how to "conceptualize or measure human agency" (Healy, 2013, p. 352, emphasis added). Not surprisingly, the term agency "has maintained an elusive albeit resonant, vagueness" in the social sciences (Bottoms, 2006, p. 253). I believed some years ago when Paternoster and I talked about his thoughts on human agency that he was making an important contribution to the field, independent of his distinction between reasons and causes. Yet, it is more than possible "for the observer (or, sometimes, an actor) to offer a causal history of the agent's reasons... what Malle calls a CHR (causal history of reasons) explanations" (Bottoms, 2006, p. 255). It is also possible that as an intentional actor an action I wish to take is reliant on some enabling factor; e.g., I want to drive to the beach which is ten miles away but I need a car that has enough gas to allow me to drive there. Thus, a "reasons" explanation can in principle always be backed by what Malle would call a CHR explanation; and such an explanation, "while formally voluntaristic, could as well have been causal."...Thus, Barnes... offers compatibilism as an option, "the view that the existence of voluntary actions 
sensibly described as involving will or agency is not inconsistent with determinism (Barnes, 2000, p. 32)." (Bottoms, 2006, p. 256). ${ }^{7}$

Thomas et al. seem to interpret Paternoster as offering an incompatibilist view of human agency. Barnes $(2000,31)$ notes that this could work "if it were based on a conception of free choice as wholly uncaused and unpredictable. Then the distinction of the caused and the chosen could be used to mark the bounds of predictive explanatory science in the human realm. But this is a position rarely taken in the social sciences for the obvious reason that it implies the redundancy of that project. Theorists in the social sciences are bound to become involved, however reluctantly, in predictive and/or explanatory projects...But once theories become predictive or explanatory it is going to be asked whether they are not "really" causal theories, adorned in a wholly superfluous metaphysics of agency; for our familiar discourse of prediction and explanation is a broadly causal one. And if reply is made that human actions, in the last analysis, "could have been otherwise," that, as it stands, will count merely as another assertion of the metaphysics in question." (see also Bottoms pp. 259-260). Thomas et al.'s argument that there is, therefore, a fundamental incompatibility between their (and Paternoster's) version of agency and positivism rests on a key assumption: that there is no meaningful variation in agency from person to person or across situations. That is, people do not vary with respect to their capacity to imagine, set goals, and act purposely. The problem for Thomas et al., of course, is that's an empirical question. ${ }^{8}$ And the only way to determine whether Thomas et al. are correct about that is to develop an operational measure and assess if it varies from person to person. If it does, as others have argued before, then their argument falls flat. ${ }^{9}$ As Manski (2019, p. 7637) reminds us, conclusions are equal to the sum of assumptions and data. Thomas et al. are making assumptions, but data remain part of the pathway to conclusions. And while different people are entitled to different sets of assumptions, it remains the case that the data are the data and without data, one has no conclusion to reach.

In their excellent article assessing how changes in identity and/or social structure predict subsequent changes in criminal activity with data from Dutch offenders, Hickert et al. (2021) observe that there is a "renewed debate on agency/identity

\footnotetext{
7 Another issue in all this is that the "reasons" argument assumes we know our reasons. Of course, in many theories, our reasons are not intentional in the rationalized, awareness sense. We often construct reasons when asked, in retrospect. Thus, one needs to be careful in the sense that the analysis of meaning is not the same as causal analysis. That is, the meaning I attribute to actions is not necessarily why I did the act. Put differently and even more devastating to Thomas et al.'s argument is that "reasons" and meaning are themselves situated and social.

8 As Tittle and Paternoster (2000, p. 545, emphasis added) noted: "When we act, we often, if not usually, do so to accomplish some purpose, to respond to some immediate mandate, or because we have a habit of behaving that way....any complete or successful theory of deviant or criminal behavior must account for the variation in the strength of the impulse to do or neglect to do the things that are to be explained by the theory.".

9 Thomas et al. are right about one thing: assumptions do matter. And the only way for Thomas et al. to know whether or not their assumption is correct is to test it using the very approach they dismiss as being fundamentally at odds with their own assumptions. I am sure that I am not the only one who appreciates this irony. That aside, Thomas et al. simply retreat to the scientifically useless safety of an unfalsifiable idea.
} 
(Paternoster, 2017) versus external factors (Cullen, 2017) in behavior change [that] has led to recent discourse advocating for models that integrate internal and external factors (e.g., Brezina, 2019; Piquero, 2020)" (p. 102, emphasis in original). Both Brezina and I have attempted to find some common ground in the positions of Paternoster and Cullen, which I remain convinced offer more to criminologists in tandem than in isolation. In fact, Paternoster's advocacy of a teleological explanation does not, as he writes, "deny that there are causal laws or useful causal explanations, just that there are other equally valid explanations for human conduct, explanations that are far more consistent with volitional understandings of human agency" (p. 366, emphasis added). ${ }^{10}$ Paternoster never said that there was a choice between agency as an emergent property of social institutions and agency as a concept that can be measured. He was too much a student of the philosophy of science to make such a rookie mistake. ${ }^{11} \mathrm{I}$ am heartened that Hickert et al. "fully agree with recent calls for further examination of the reciprocal relationship between structural conditions and agency/identity (Brezina, 2019; Piquero, 2020; Williams \& Schaefer, 2020)" (p. 102), as it resonates well with Felson's (1986, p. 119) reminder that "[p]eople make choices, but they cannot choose the choices available to them," something that economists have long recognized.

As Paternoster (2017, p. 370) noted at the end of his article: “...everyone should agree that a more detailed and open conversation and discussion about what human agency is or is not, and the implication of one's conceptualization of human agency for theory in criminology is long overdue." I think his essay has done that and done it well and did not need others "speaking on his behalf." After all, we stand on the shoulders of giants. We do not speak on their behalf.

There is a place for agency, a place for causation, a place for both in our thinking about crime. If the coronavirus pandemic has told us anything, it is that agency and causation are not mutually exclusive. The key for us is to understand how they intermix to affect behavior.

Acknowledgements I am grateful to Robert Brame, John H. Laub, Daniel S. Nagin, Robert J. Sampson, Travis Pratt, Charles Wellford, and P-O Wikström for their useful comments and suggestions. I also thank Ray Paternoster, my mentor and friend for over 25 years.

\footnotetext{
10 A somewhat related idea about Thomas et al.'s "either/or but not both" perspective may be found in the literature attempting to understand disproportionate minority confinement. The main line of argument here is that it could be due to differential enforcement, differential offending-or more likely some conviction of the two (Piquero, 2008). Similar arguments can be found in the literature about the extent to which genes or environments predict human behavior, including criminal activity. Both obviously do. And so is the case for matters at hand, social-situational opportunity structures and purposeful human action matter for desistance from crime (see Williams \& Schaefer, 2021).

11 Readers should obviously see how Paternoster was influenced by Parsons' action theory which provides a foundation for merging agency and structuralism in modern social sciences as opposed to philosophy. In short, "[e]ach action is the action of an actor, and it takes place in a situation consisting of objects" (Parsons and Shils, 1962, p. 54). For those readers who are new to Parsons or need a refresher, it is useful to highlight the four points in the theory of action, which are as follows: "(1) Behavior is oriented to the attainment of ends or goals or other anticipated states of affairs. (2) It takes place in situations. (3) It is normatively regulated. (4) It involves the expenditure of energy or effort or "motivation" (which may be more or less organized independently of its involvement in action)" (p. 53).
} 


\section{References}

Barnes, B. (2000). Understanding agency: Social theory and responsible action. Sage.

Bottoms, A. (2006). Desistance, social bonds, and human agency: A theoretical exploration. In (Eds) Wikström, P-O. \& Sampson, R.J. The explanation of crime: Context, mechanisms and development. Cambridge University Press.

Cullen, F. T. (2017). Choosing our criminological future: Reservations about human agency as an organizing concept. Journal of Developmental and Life Course Criminology, 3, 373-379.

Emirbayer, M., \& Mische, A. (1998). What is agency? American Journal of Sociology, 103, 962-1023.

Felson, M. (1986). Linking criminal choices, routine activities, informal control, and criminal choices. In D. B. Cornish \& R. V. Clarke (Eds.), The reasoning criminal: Rational choice perspectives on offending (pp. 119-128). Springer-Verlag.

Goller, M. (2017). Human agency at work: An active approach towards expertise development. Springer VS.

Goller, M., \& Harteis, C. (2017). Human agency at work: Towards a clarification and operationalization of the concept. In M. Goller and S. Paloniemi (Eds.), Agency at work. Professional and Practicebased Learning, vol 20. Springer. https://doi.org/10.1007/978-3-319-60943-0_5.

Gottfredson, M., \& Hirschi, T. (2020). Modern control theory and the limits of criminal justice. Oxford University Press.

Healy, D. (2013). Changing fate? Agency and the desistance process. Theoretical Criminology, 17, 557-574.

Hickert, A., Bushway, S., Nieuwbeerta, P., \& Dirkzwager, A. J. E. (2021). Confinement as a two-stage turning point: Do changes in identity or social structure predict subsequent changes in criminal activity. Criminology, 59, 73-109.

Hirschi, T. (1986). On the compatibility of rational choice and social control theories of crime. In D. B. Cornish \& R. V. Clarke (Eds.), The reasoning criminal: Rational choice perspectives on offending (pp. 105-117). Springer-Verlag.

Hirschi, T. (2004). Self-control and crime. In R. F. Baumeister \& K. D. Vohs (Eds.), Handbook of selfregulation: Research, theory, and applications (pp. 537-552). Guilford Press.

Laub, J. H. (2006). Edwin H. Sutherland and the Michael-Adler Report: Searching for the soul of criminology seventy years later. Criminology, 44, 235-257.

Laub, J. H., \& Sampson, R. J. (2003). Shared beginnings, divergent lives: Delinquent boys to age 70. Harvard University Press.

Lilly, J. R., Cullen, F. T., \& Ball, R. A. (2006). Criminological theory: Contexts and consequences. Sage Publishers.

Manski, C. (2019). Communicating uncertainty in policy analysis. PNAS, 116, 7634-7641.

Marcus, B. (2003). An empirical assessment of the construct validity of two alternative self-control measures. Educational and Psychological Measurement, 63, 674-706.

Monahan, K., Steinberg, L., \& Piquero, A. R. (2015). Juvenile justice policy and practice: A developmental perspective. In M. Tonry (Ed.), Crime and justice: A review of research (pp. 577-619). University of Chicago Press.

Moore, J. W. (2016). What is the sense of agency and why does it matter? Frontiers in Psychology, 7, 1272. https://doi.org/10.3389/fpsyg.2016.01272.

Nagin, D. S. (2007). Moving choice to center stage in criminological research and theory. Criminology, $45,259-272$.

Parsons, T., \& Shils, E. A. (Eds.). (1962). [1951]. Toward a general theory of action: Theoretical foundations for the social sciences. Harper \& Row Publishers.

Paternoster, R. (2017). Happenings, acts, and actions: Articulating the meaning and implications of human agency for criminology. Journal of Developmental and Life-Course Criminology, 3, 350-372.

Paternoster, R., \& Bushway, S. (2009). Desistance and the "feared self": Toward an identity theory of criminal desistance. Journal of Criminal Law and Criminology, 1103-1156.

Paternoster, R., \& Pogarsky, G. (2009). Rational choice, agency, and thoughtfully reflective decision making: The short and long-term consequences of making good choices. Journal of Quantitative Criminology, 25, 103-127.

Piquero, A. R. (2008). Disproportionate minority confinement. The Future of Children, 18, 59-79. 
Piquero, A.R. (2020). A place for agency, a place for positivism, a place for both over the life course. Journal of Developmental and Life-Course Criminology, 6, 245-250.

Piquero, A. R., \& Bouffard, J. (2007). Something old, something new: A preliminary investigation of Hirschi's redefined self-control. Justice Quarterly, 24, 1-27.

Piquero, A. R., MacIntosh, R., \& Hickman, M. (2000). Does self-control affect survey response? Applying exploratory, confirmatory, and item response theory analysis to Grasmick et al's self-control scale. Criminology, 38, 897-930.

Piquero, A. R., Paternoster, R., Pogarsky, G., \& Loughran, T. (2011). Elaborating the individual difference component in deterrence theory. Annual Review of Law and Social Science, 7, 335-360.

Tapal, A., Oren, E., Dar, R., \& Eitam, B. (2017). The sense of agency scale: A measure of consciously perceived control over one's mind, body, and the immediate environment. Frontiers in Psychology, 8, 1-11. https://doi.org/10.3389/fpsyg.2017.01552.

Thomas, K. J., Loughran, T. A., \& Piquero, A. R. (2013). Do individual characteristics explain variation in sanction risk updating among serious juvenile offenders? Advancing the logic of differential deterrence. Law \& Human Behavior, 37, 10-21.

Tittle, C.R. (1995). Control balance: Toward a general theory of deviance. Westview.

Tittle, C. R., \& Paternoster, R. (2000). Social deviance and crime: An organizational and theoretical approach. Roxbury Publishing Company.

Vohs, K.D., \& Piquero, A.R. (2021). Self-control at 200 miles per hour: Steering and breaking to achieve optimal outcomes during adolescence. Current Directions in Psychological Science, 30, 351-357.

Wikström P-O. (2005). The social origins of pathways in crime: Towards a developmental ecological action theory of crime involvement and its changes. In D.P. Farrington (Ed.), Integrated developmental and life-course theories of offending (advances in criminological theory), Volume 14. New Brunswick, NJ: Transaction Publishers.

Wikström P-O. (2006). Individuals, settings and acts of crime. Situational mechanisms and the explanation of crime. In (Eds) Wikström P-O \& Sampson Robert. J. The explanation of crime: context, mechanisms and development. Cambridge University Press.

Wikström P-O. (2017). Character, circumstances, and the causes of crime. In (Eds) Liebling A., Maruna S. \& McAra L.: The Oxford handbook of criminology. Oxford University Press.

Wikström P-O. \& Treiber K. (2018). The dynamics of change. Criminogenic interactions and life-course patterns of crime. In (Eds) D. P. Farrington, L. Kazemian \& A. Piquero: The Oxford handbook of developmental and life-course criminology. Oxford University Press.

Williams, G. C., \& Schaefer, L. (2021). Expanding desistance theories through the integration of offender strategies. Journal of Crime and Justice, 44, 16-32.

Publisher's Note Springer Nature remains neutral with regard to jurisdictional claims in published maps and institutional affiliations. 